\title{
Social learning research outside the laboratory: How and why?
}

\author{
RACHEL L. KENDAL \\ University of Durham, Durham, England \\ Bennett G. Galef \\ McMaster University, Hamilton, Ontario, Canada \\ AND \\ Carel P. van Schaik \\ Universität Zürich, Zürich, Switzerland
}

Social learning enables both human and nonhuman animals to acquire information relevant to many biologically important activities: foraging (Galef \& Giraldeau, 2001; Mesoudi \& O’Brien, 2008), mate choice (Jones, DeBruine, Little, Burriss, \& Feinberg, 2007; Laland, 1994; White, 2004), conflict (Peake \& McGregor, 2004), and predator avoidance (Griffin, 2004). Although use of social information is not inherently adaptive (Boyd \& Richerson, 1985; Laland, 2004), its frequent roles in the development in animals of both innovations (sensu Reader \& Laland, 2003) and routine skills (Jaeggi et al., 2010; Krakauer, 2005), as well as its exceptional prevalence in human societies, suggest the importance of social information in biological and cultural evolution. In fact, socially learned information may have been instrumental in promoting the biological evolution of cognitive capacities (Whiten \& van Schaik, 2007), and variation in use of social learning as an inheritance system may be responsible for the disparity between human and nonhuman animals in the complexity of their cultural behavior (Tomasello, 1999; Whiten \& van Schaik, 2007).

This special issue of Learning \& Behavior has two inextricably linked foci: first, identification of social learning in natural contexts, and second, consideration of the implications of current findings from the study of social learning in natural contexts for understanding the evolution of cultural capacities in the animal kingdom, of which humans are an integral part. Although there are wellestablished, sophisticated methods for documenting social learning in the laboratory (see the issue of Philosophical Transactions B edited by Smith, Kalish, Griffiths, \& Lewandowsky, 2008), laboratory studies often have limited ecological validity and are frequently not practicable, especially with large or endangered species (Figure 1). Most importantly, without an understanding of social learning in the context in which it evolved, we cannot hope to elucidate the interaction between biological and cultural evolution. Thus, identification of social learning in free-living populations of animals is a necessary first step in our quest for knowledge. Unfortunately, until recently, researchers have been forced to rely on expert opinion when deciding what proportion of the behavioral variation observed in natural contexts can plausibly be accounted for by cultural, as opposed to ecological and genetic, processes. The result has been heated debate, which some have gone so far as to describe as "war" (McGrew, 2002), about the reality of purported cultural behaviors in animals.

The disagreement over the utility of describing local specific behaviors as cultural is a result of the inability of the approaches previously available to researchers who study free-living populations (e.g., the group-contrasts method or method of exclusion pioneered by Whiten et al., 1999; quantitative analyses pioneered by Sargeant \& Mann, 2009; Whitehead, 2009) to conclusively determine whether social learning is required in order to produce the observed patterns of behavioral variation. Despite the increasing number of high-profile, and oft-debated, reports of "culture" in wild animals (Hohmann \& Fruth, 2003; Leca, Gunst, \& Huffman, 2007; Perry et al., 2003; Rendell \& Whitehead, 2001; van Schaik, Ancrenaz, et al., 2003; Whiten et al., 1999), until we have tools that can provide widely accepted evidence for social learning, controversy and confusion will reign both as to the extent of culture in animals and the utility of studies of animal traditions in understanding animal and human evolution (Galef, 2009).

Over the last decade, and especially in the last few years, a variety of methods have emerged for identifying (the consequences of) social learning in natural contexts

R. L. Kendal, rachel.kendal@durham.ac.uk 


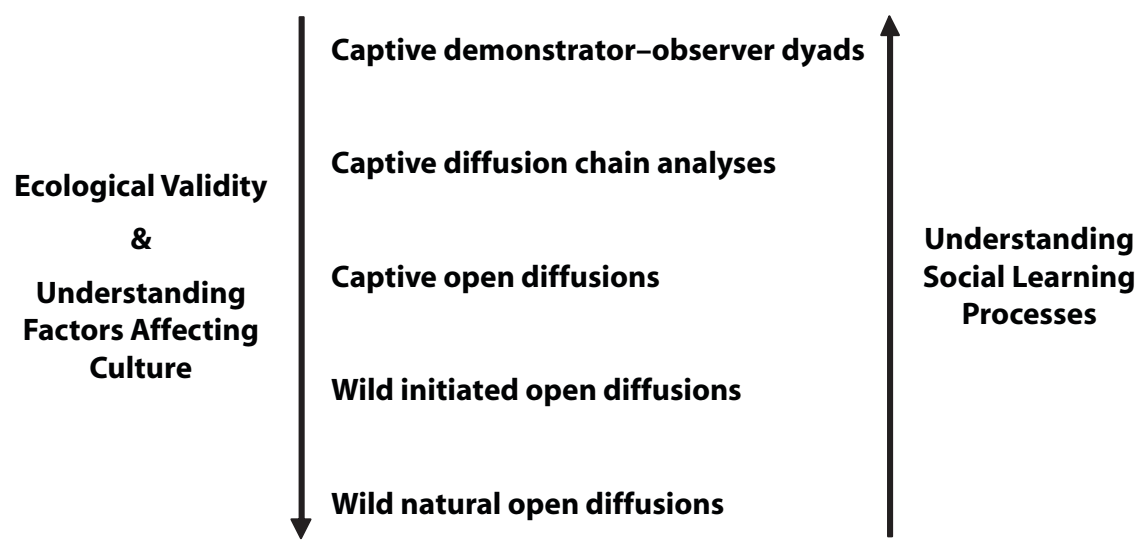

Figure 1. An illustration of how methods for identifying social learning lie on a continuum. At the top of the list, there is good control and understanding of social learning processes and relatively little ecological validity, whereas toward the bottom there is increased ecological validity but decreasing likelihood of even distinguishing social from asocial learning. The term initiated open diffusions refers to cases in which the experimenter provides a novel task, thus initiating the inception and spread of information. For further discussion of social diffusion experiments, see Whiten and Mesoudi (2008) and Mesoudi and Whiten (2008).

(i.e., in social groups, whether in the wild or captivity and whether involving one or multiple groups). These methods are summarized in Table 1, which, although it is not exhaustive, may be used as a guide to the ever-growing toolbox available for the capture of social learning in natural contexts. It is timely to bring such methods together to highlight and assess this growing toolkit, available to researchers interested in both animal and human culture. These methods will be a focus throughout this special issue, and include (1) intensive field observation, allowing culture to be inferred as a consequence of eliminating any substantial role for ecology, genetics, and developmental constraints in producing observed variation (in this issue, see Holzhaider, Hunt, \& Gray, 2010; Lonsdorf \& Bonnie, 2010); (2) theoretical/statistical methods for assessing the likelihood of asocial learning being responsible for an observed pattern of behavior, which permit inference of social learning when asocial learning has been deemed improbable (Franz \& Nunn, 2010; Hoppitt, Kandler, Kendal, \& Laland, 2010; R. L. Kendal et al., 2010); (3) fitting mathematical models to phylogenetic data (Lycett, 2010); and (4) use of novel field (Reader \& Biro, 2010; Thornton \& Raihani, 2010) and naturalistic (Caldwell \& Millen, 2010; Flynn \& Whiten, 2010) experiments. These new methods, and the associated findings, involve not only a wide array of species (including fish, birds, mammals, nonhuman primates, and both child and adult humans), but also a wide array of factors that may have affected both biological and cultural evolution (including different social learning processes, ecology, social systems, developmental constraints, and individual differences).

This special issue is the first both to focus on the new and exciting methods now available to the social learning researcher (summarized in Table 1) and to emphasize the potential and utility of ecologically valid studies of cultural transmission. Although we still face a challenge in ascertaining which social learning processes underpin the transmission of behavior patterns in free-living ani- mals (see Hill, 2010, in this issue; but see J. R. Kendal, Kendal, \& Laland, 2007; Thornton, Samson, Laland, \& Hoppitt, 2010), we have come far, at least in our ability to identify social learning in natural contexts. Note, however, that despite any methodological shortcomings, previous field studies have shown what minimally constitutes animal cultures or traditions, allowing us to infer the most likely foundation from which human culture has arisen. The proliferation of methods for capturing social learning in natural contexts that is highlighted here would not have occurred without these earlier field studies, and indeed many of the new methods may be applied fruitfully to existing data sets. For example, the option-bias analysis method (R. L. Kendal et al., 2010) is in essence a quantitative version, using individual-level information, of the widely used ethnographic or group-contrasts method (van Schaik, Ancrenaz, et al., 2003; Whiten et al., 1999).

We hope the reader will agree that the field of social learning has reached a point at which the efforts of researchers from diverse backgrounds, producing a coalescence of statistical tools, field and laboratory approaches, and insights regarding a variety of species, are enabling the study of the evolution of culture in ways unimagined when, over half a century ago, the social transmission of naturally occurring and experimentally seeded innovations was first described in wild populations (Fisher \& Hinde, 1949; Kawai, 1965). Furthermore, as a result of the creation of methodologies allowing valid comparisons of humans and nonhumans, the present collection of articles may help bridge the divide between biological anthropologists, who often deem social learning sufficient for defining traditions or culture, and social/cultural anthropologists, who most often assert that social learning is necessary, but not sufficient, for the emergence of culture (Hill, 2010).

The findings of the research highlighted here enter into the present debate regarding the extent of culture in animals and the processes by which the potent cultural capacity of humans has evolved. The field of animal social learning 


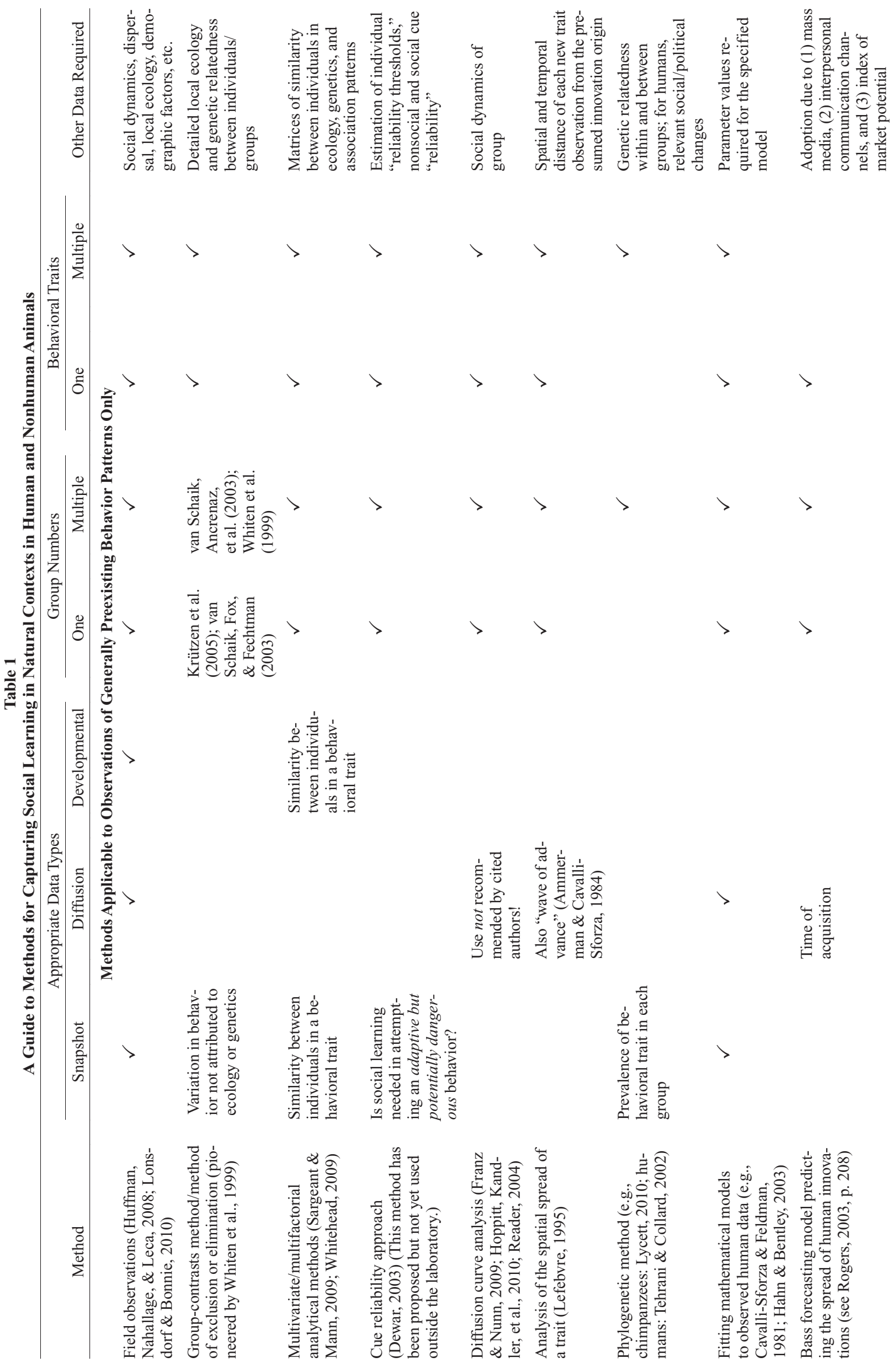




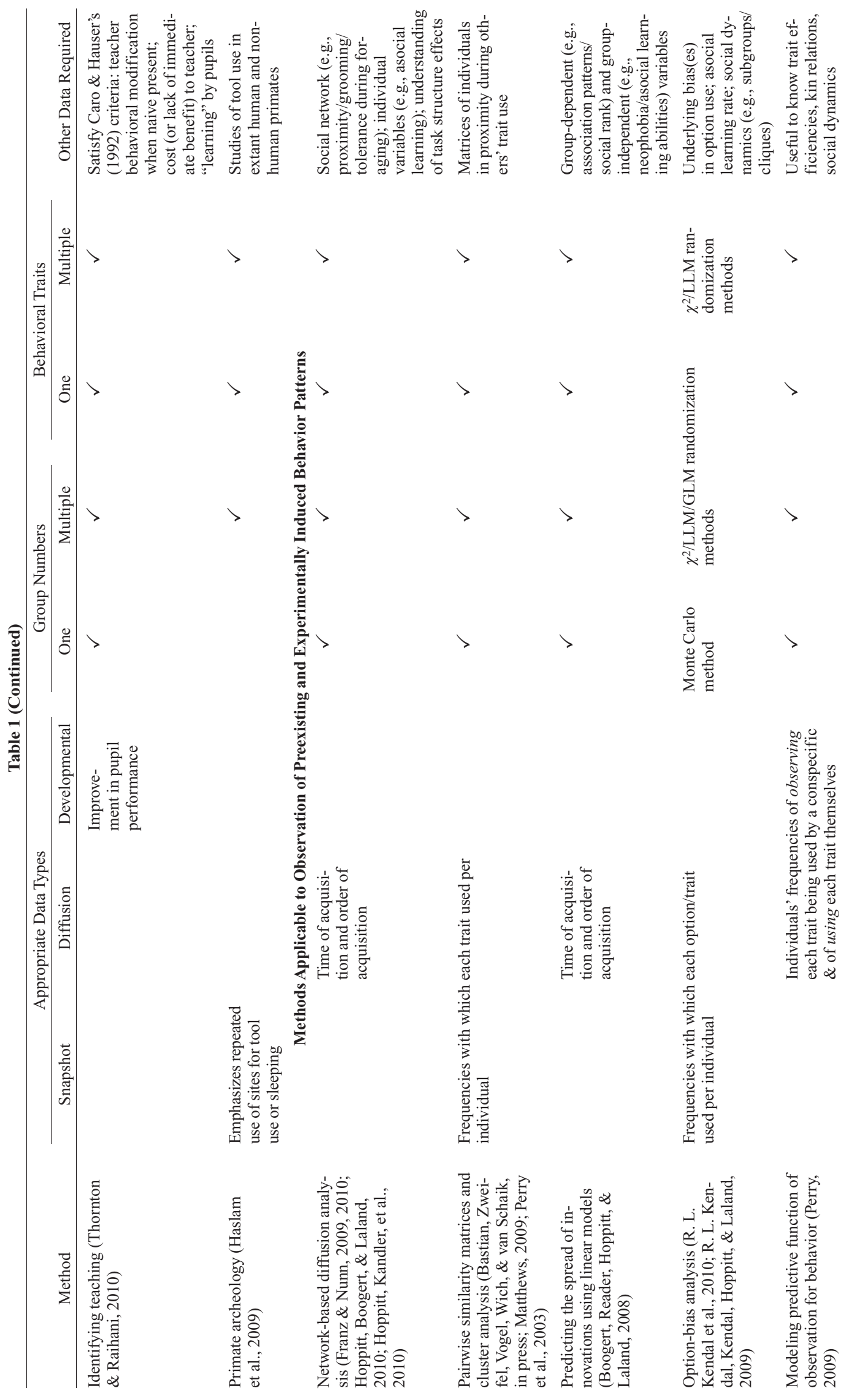




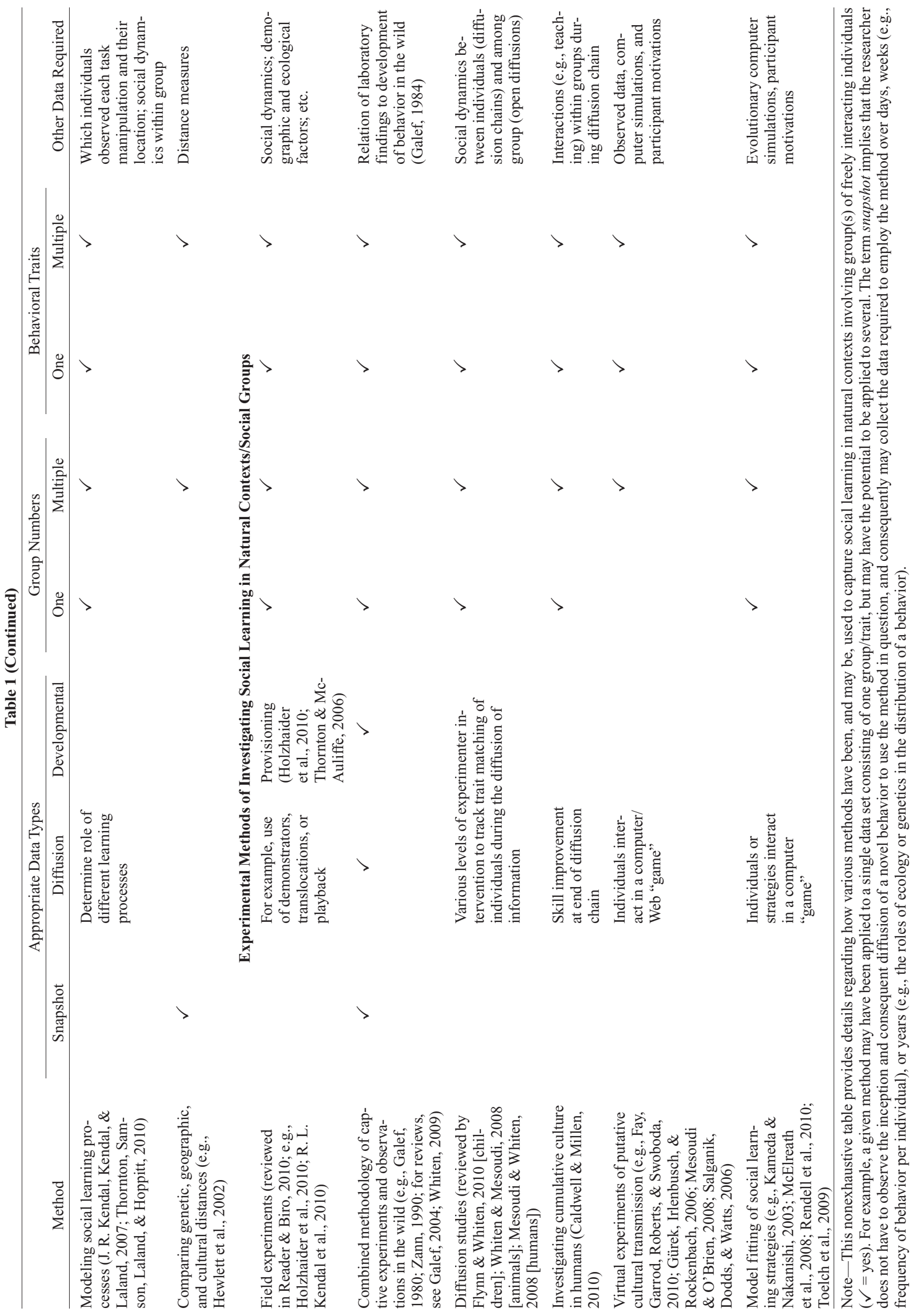


needs to provide an estimate of the importance of social learning and traditions in the development of the behavioral repertoires of natural populations, as well as (1) a theory predicting the conditions in which traditions do and do not occur (e.g., R. L. Kendal et al., 2010; Lonsdorf \& Bonnie, 2010; Reader \& Biro, 2010) and (2) a theoretical framework for understanding the evolution of different mechanisms of social learning (e.g., teaching [Thornton \& Raihani, 2010] or collaboration [Flynn \& Whiten, 2010]). These may be distant vistas, but this collection of articles highlights the tentative steps the field is making toward their realization.

It remains to be seen whether traditions in animals provide any insight into the evolution of human culture. On the one hand, knowledge of animal traditions does not inform the study of human culture, because the mechanisms that maintain human culture and animal traditions are probably not homologous (Galef, 2009). Thus, cognitively more advanced species possess a variety of social learning mechanisms used in the acquisition of skills and knowledge. Consequently, it is inevitable that humans and other animals use different sets of mechanisms when engaging in social learning (Subiaul, 2007). For example, it is becoming clear that teaching plays an infinitely greater role in the acquisition of behavior in humans than in our great ape relatives, although, interestingly, behaviors that meet the criteria explicit in the most frequently used definition of teaching (Caro \& Hauser, 1992) are also found in some unexpected places (e.g., meerkats, pied babblers, bees, ants, cats: see Thornton \& Raihani, 2010; for a review, see Hoppitt et al., 2008). Indeed, the emergence of novel social learning mechanisms in different lineages is to be expected, and describing and analyzing such emergent mechanisms is an important part of the exploration of species differences. Obviously, taxa lacking particular mechanisms of social learning are incomplete models for taxa that do possess them.

On the other hand, even if the mechanisms used to establish and maintain cultural phenomena are clearly not homologous, the phenomena of traditions or cultures themselves may well be homologous between humans and some nonhuman species. Indeed, exploration of differences in the mechanisms supporting traditions in different lineages will suggest selective contexts in which novel mechanisms could have arisen. An understanding of social learning in wild animals may therefore provide a general theory of cultural evolution highlighting which cultural features are present and absent in nonhuman species and the causes of the unique cultural capacity of humans (Hill, 2010). The cultural repertoires of humans are far larger than those of any nonhuman animal (Lycett, 2010), probably because of the presence of cumulative culture in humans (Caldwell \& Millen, 2010) and its absence in other animals (but see Holzhaider et al., 2010). Still, exploration of differences between the mechanisms and breadth of human and animal cultures should inform scenarios of human evolution, just as differences between the traditions of monkeys and great apes, or of corvid and noncorvid birds, should inform scenarios of the evolution of culture in those lineages.
Knowledge of social learning in natural contexts also has implications for ethics, philosophy, and politics. Continuity of the human and the nonhuman animal mind affects ethical considerations in animal welfare. Similarly, an understanding of social learning in natural circumstances can be used to enhance the conservation and management of species facing extinction, as well as influencing conservation priorities through increasing awareness of the existence of not only genetic, but also cultural diversity in animals (see Whitehead, 2010, in this issue).

We hope that this collection of articles, along with those summarized in Table 1, provides at the least a first step toward general acceptance of a methodological toolbox for identifying social learning in natural contexts. Indeed, we are convinced that the only way to bring peace to the culture "wars" (McGrew, 2002) is to stimulate further rigorous study of traditions (or culture) in naturalistic contexts.

\section{AUTHOR NOTE}

For ensuring smooth running of the IPS symposium, from which this special issue grew, R.L.K. is extremely grateful to Jeremy Kendal and Lydia Hopper for stepping into the breach. We thank Jamie Tehrani, Gill Vale, Natalie le Brun, and Lara Wood for assistance in reviewing the contributed manuscripts, and Will Hoppitt, Jeremy Kendal, and Alex Mesoudi for insights regarding this introduction. R.L.K. is supported by a Royal Society Dorothy Hodgkin Fellowship, and C.P.v.S. by SNF Grants 31003A-111915 and 3100A0-116848/1. Correspondence related to this article may be sent to R. L. Kendal, Centre for the Coevolution of Biology and Culture, Department of Anthropology, University of Durham, South Road, Durham DH1 3LE, U.K. (e-mail: rachel.kendal@) durham.ac.uk).

\section{REFERENCES}

Ammerman, A. J., \& Cavalli-Sforza, L. L. (1984). The neolithic transition and the genetics of populations in Europe. Princeton, NJ: Princeton University Press.

Bastian, M. L., Zweifel, N., Vogel, E. R., Wich, S. A., \& VAn Schaik, C. P. (in press). Diet traditions in wild orangutans. American Journal of Physical Anthropology.

Boogert, N. J., Reader, S. M., Hoppitt, W., \& Laland, K. N. (2008). The origin and spread of innovations in starlings. Animal Behaviour, 75, 1509-1518.

Boyd, R., \& Richerson, P. J. (1985). Culture and the evolutionary process. Chicago: University of Chicago Press.

Caldwell, C. A., \& Millen, A. E. (2010). Human cumulative culture in the laboratory: Effects of (micro) population size. Learning \& Behavior, 38, 310-318.

CARo, T. M., \& Hauser, M. D. (1992). Is there teaching in nonhuman animals? Quarterly Review of Biology, 67, 151-174

Cavalli-Sforza, L. L., \& Feldman, M. W. (1981). Cultural transmission and evolution: A quantitative approach. Princeton, NJ: Princeton University Press.

Dewar, G. (2003). The cue reliability approach to social transmission: Designing tests for adaptive traditions. In D. M. Fragaszy \& S. Perry (Eds.), The biology of traditions: Models and evidence (pp. 127-158). Cambridge: Cambridge University Press.

Fay, N., Garrod, S., Roberts, L., \& Swoboda, N. (2010). The interactive evolution of human communication systems. Cognitive Science, 34, 351-386.

FISHER, J., \& HindE, R. A. (1949). The opening of milk bottles by birds. British Birds, 42, 347-357.

FlynN, E., \& Whiten, A. (2010). Studying children's social learning experimentally "in the wild." Learning \& Behavior, 38, 284-296.

Franz, M., \& NunN, C. L. (2009). Network-based diffusion analysis: A new method for detecting social learning. Proceedings of the Royal Society B, 276, 1829-1836.

FranZ, M., \& NunN, C. L. (2010). Investigating the impact of observa- 
tion errors on the statistical performance of network-based diffusion analysis. Learning \& Behavior, 38, 235-242.

GALEF, B. G., JR. (1980). Diving for food: Analysis of a possible case of social learning in wild rats (Rattus norvegicus). Journal of Comparative \& Physiological Psychology, 94, 416-425.

GALEF, B. G., JR. (1984). Reciprocal heuristics: A discussion of the relationship of the study of learned behavior in laboratory and field. Learning \& Motivation, 15, 479-493.

GALEF, B. G., JR. (2004). Approaches to the study of traditional behaviors of free-living animals. Learning \& Behavior, 32, 53-61.

Galef, B. G.[, JR.] (2009). Culture in animals? In K. N. Laland \& B. G. Galef (Eds.), The question of animal culture (pp. 222-246). Cambridge, MA: Harvard University Press.

Galef, B. G., JR., \& GiraldeaU, L.-A. (2001). Social influences on foraging in vertebrates: Causal mechanisms and adaptive functions. Animal Behaviour, 61, 3-15.

Griffin, A. S. (2004). Social learning about predators: A review and prospectus. Learning \& Behavior, 32, 131-140.

Gürek, O., Irlenbusch, B., \& Rockenbach, B. (2006). The competitive advantage of sanctioning institutions. Science, 312, 108-111.

Hahn, M. W., \& Bentley, R. A. (2003). Drift as a mechanism of cultural change: An example from baby names. Proceedings of the Royal Society B, 270, S1-S4.

Haslam, M., Hernandez-Aguilar, A., Ling, V., Carvalho, S., De la Torre, I., DeStefano, A., Et AL. (2009). Primate archaeology. Nature, 460, 339-344.

Hewlett, B. S., De Silvestri, A., \& Guglielmino, C. R. (2002). Semes and genes in Africa. Current Anthropology, 43, 313-321.

HILL, K. (2010). Experimental studies of animal social learning in the wild: Trying to untangle the mystery of human culture. Learning \& Behavior, 38, 319-328.

HohmanN, G., \& Fruth, B. (2003). Culture in bonobos? Betweenspecies and within-species variation in behavior. Current Anthropology, 44, 563-571.

Holzhaider, J. C., Hunt, G. R., \& Gray, R. D. (2010). Social learning in New Caledonian crows. Learning \& Behavior, 38, 206-219.

Hoppitt, W., Boogert, N. J., \& Laland, K. N. (2010). Detecting social transmission in networks. Journal of Theoretical Biology, 263, 544555. doi:10.1016/j.jtbi.2010.01.004

Hoppitt, W., Brown, G. R., Kendal, R. L., Rendell, L., Thornton, A., Webster, M. M., \& Laland, K. N. (2008). Lessons from animal teaching. Trends in Ecology \& Evolution, 23, 486-493.

Hoppitt, W., Kandler, A., Kendal, J. R., \& Laland, K. N. (2010). The effect of task structure on diffusion dynamics: Implications for diffusion curve and network-based analyses. Learning \& Behavior, 38, 243-251.

Huffman, M. A., Nahallage, C. A. D., \& LeCa, J.-B. (2008). Cultured monkeys: Social learning cast in stones. Current Directions in Psychological Science, 17, 410-414.

Jaeggi, A., Dunkel, L., van NoordwiJk, M. A., Wich, S. A., Sura, A. A. L., \& van Schaik, C. P. (2010). Social learning of diet and foraging skills by wild immature Bornean orangutans: Implications for culture. American Journal of Primatology, 72, 62-71.

Jones, B. C., DeBruine, L. M., Little, A. C., Burriss, R. P., \& FeinBERG, D. R. (2007). Social transmission of face preferences among humans. Proceedings of the Royal Society B, 274, 899-903.

Kameda, T., \& NAKANISHI, D. (2003). Does cultural/social learning increase human adaptability? Rogers' question revisited. Evolution \& Human Behavior, 24, 242-260.

KAWAI, M. (1965). Newly acquired pre-cultural behaviour of the natural troop of Japanese monkeys on Koshima Islet. Primates, 6, 1-30.

Kendal, J. R., Kendal, R. L., \& LaLAND, K. N. (2007). Quantifying and modelling social learning processes in monkey populations. International Journal of Psychology \& Psychological Therapy, 7, 123-138.

Kendal, R. L., Custance, D. M., Kendal, J. R., Vale, G., Stoinski, T. S., Rakotomalala, N. L., \& Rasamimanana, H. (2010). Evidence for social learning in wild lemurs (Lemur catta). Learning \& Behavior, 38, 220-234

Kendal, R. L., Kendal, J. R., Hoppitt, W., \& Laland, K. N. (2009). Identifying social learning in animal populations: A new "optionbias" method. PLOS ONE, 4, e6541.

KraKaUer, E. B. (2005). Development of aye-aye (Daubentonia mada- gascariensis) foraging skills: Independent exploration and social learning. Unpublished $\mathrm{PhD}$ dissertation, Duke University.

Krützen, M., Mann, J., Heithaus, M. R., Connor, R. C., Bejder, L., \& SHERWIN, W. B. (2005). Cultural transmission of tool use in bottlenose dolphins. Proceedings of the National Academy of Sciences, 102, 8939-8943.

LaLAND, K. N. (1994). Sexual selection with a culturally transmitted mating preference. Theoretical Population Biology, 45, 1-15.

LALAND, K. N. (2004). Social learning strategies. Learning \& Behavior, 32, 4-14.

Leca, J.-B., Gunst, N., \& Huffman, M. A. (2007). Japanese macaque cultures: Inter- and intra-troop behavioural variability of stone handling patterns across 10 troops. Behaviour, 144, 251-281.

LEFEBVRE, L. (1995). The opening of milk bottles by birds: Evidence for accelerating learning rates, but against the wave-of-advance model of cultural transmission. Behavioural Processes, 34, 43-54.

LonsDorf, E. V., \& BonNIE, K. E. (2010). Opportunities and constraints when studying social learning: Developmental approaches and social factors. Learning \& Behavior, 38, 195-205.

LyCETT, S. J. (2010). The importance of history in definitions of "culture": Implications from phylogenetic approaches to the study of social learning in chimpanzees. Learning \& Behavior, 38, 252-264.

Matthews, L. J. (2009). Intragroup behavioural variation in whitefronted capuchin monkeys (Cebus albifrons): Mixed evidence for social learning inferred from new and established analytical methods. Behaviour, 146, 295-324.

McElreath, R., Bell, A. V., Efferson, C., Lubell, M., Richerson, P. J., \& WARING, T. (2008). Beyond existence and aiming outside the laboratory: Estimating frequency-dependent and pay-off-biased social learning strategies. Philosophical Transactions of the Royal Society B, 363, 3515-3528. doi:10.1098/rstb.2008.0131

McGrew, W. C. (2002). Ten dispatches from the chimpanzee culture wars. In F. B. M. de Waal \& P. L. Tyack (Eds.), Animal social complexity. Cambridge, MA: Harvard University Press.

Mesoudi, A., \& O'Brien, M. J. (2008). The cultural transmission of Great Basin projectile point technology I: An experimental simulation. American Antiquity, 73, 3-28.

Mesoudi, A., \& Whiten, A. (2008). The multiple roles of cultural transmission experiments in understanding human cultural evolution. Philosophical Transactions of the Royal Society B, 363, 3489-3501. doi: $10.1098 /$ rstb.2008.0129

Peake, T. M., \& McGregor, P. K. (2004). Information and aggression in fishes. Learning \& Behavior, 32, 114-121.

PERry, S. (2009). Conformism in the food processing techniques of white-faced capuchin monkeys (Cebus capucinus). Animal Cognition, 12, 705-716.

Perry, S., Baker, M., Fedigan, L., Gros-Louis, J., Jack, K., MacKinNon, K. C., ET AL. (2003). Social conventions in wild white-faced capuchin monkeys: Evidence for traditions in a neotropical primate. Current Anthropology, 44, 241-268.

READER, S. M. (2004). Distinguishing social and asocial learning using diffusion dynamics. Learning \& Behavior, 32, 90-104.

READER, S. M., \& BIRO, D. (2010). Experimental identification of social learning in wild animals. Learning \& Behavior, 38, 265-283.

Reader, S. M., \& Laland, K. N. (2003). Animal innovation: An introduction. In S. M. Reader \& K. N. Laland (Eds.), Animal innovation (pp. 3-38). Oxford: Oxford University Press.

Rendell, L., Boyd, R., Cownden, D., Enquist, M., ERiKsson, K., FeldMAN, M. W., ET AL. (2010). Why copy others? Insights from the social learning strategies tournament. Science, 328, 208-213.

Rendell, L., \& Whitehead, H. (2001). Culture in whales and dolphins. Behavioral \& Brain Sciences, 24, 309-324.

Rogers, E. M. (2003). Diffusion of innovations (5th ed.). New York: Free Press.

SalganiK, M. J., DodDS, P. S., \& WatTs, D. J. (2006). Experimental study of inequality and unpredictability in an artificial cultural market. Science, 311, 854-856.

Sargeant, B. L., \& ManN, J. (2009). From social learning to culture: Intrapopulation variation in bottlenose dolphins. In K. N. Laland \& B. G. Galef (Eds.), The question of animal culture (pp. 152-173). Cambridge, MA: Harvard University Press.

Smith, K., Kalish, M. L., Griffiths, T. L., \& Lewandowsky, S. 
(2008). Cultural transmission and the evolution of human behaviour [Special issue]. Philosophical Transactions of the Royal Society B, 363(Whole No. 1509).

Subiaul, F. (2007). The imitation faculty in monkeys: Evaluating its features, distribution and evolution. Journal of Anthropological Sciences, 85, 35-62.

Tehrani, J., \& Collard, M. (2002). Investigating cultural evolution through biological phylogenetic analysis of Turkmen textiles. Journal of Anthropological Archaeology, 21, 443-463.

Thornton, A., \& McAuliffe, K. (2006). Teaching in wild meerkats. Science, 313, 227-229.

Thornton, A., \& Raihani, N. J. (2010). Identifying teaching in wild animals. Learning \& Behavior, 38, 297-309.

Thornton, J. A. N., Samson, J., LAland, K. N., \& Hoppitt, W. (2010). Mechanisms of social transmission in wild meerkats. Manuscript in preparation.

Toelch, U., van Delft, M. J., Bruce, M. J., Donders, R., Meeus, M. T. H., \& READER, S. M. (2009). Decreased environmental variability induces a bias for social information use in humans. Evolution \& Human Behavior, 30, 32-40.

Tomasello, M. (1999). The cultural origins of human cognition. Cambridge, MA: Harvard University Press.

van Schaik, C. P., Ancrenaz, M., Borgen, G., Galdikas, B., Knott, C. D., Singleton, I., ET AL. (2003). Orangutan cultures and the evolution of material culture. Science, 299, 102-105.

van Schaik, C. P., Fox, E. A., \& Fechtman, L. T. (2003). Individual variation in the rate of use of tree-hole tools among wild orangutans: Implications for hominid evolution. Journal of Human Evolution, 44, $11-23$

White, D. J. (2004). Influences of social learning on mate-choice decisions. Learning \& Behavior, 32, 105-113.

WhiteHEAD, H. (2009). How might we study culture? A perspective from the ocean. In K. N. Laland \& B. G. Galef(Eds.), The question of animal culture (pp. 125-151). Cambridge, MA: Harvard University Press.

Whitehead, H. (2010). Conserving and managing animals that learn socially and share cultures. Learning \& Behavior, 38, 329-336.

Whiten, A. (2009). The identification and differentiation of culture in chimpanzees and other animals: From natural history to diffusion experiments. In K. N. Laland \& B. G. Galef (Eds.), The question of animal culture (pp. 99-124). Cambridge, MA: Harvard University Press.

Whiten, A., Goodall, J., McGrew, W. C., Nishida, T., Reynolds, V., SugiYama, Y., ET AL. (1999). Cultures in chimpanzees. Nature, 399, 682-685.

Whiten, A., \& Mesoudi, A. (2008). Establishing an experimental science of culture: Animal social diffusion experiments. Philosophical Transactions of the Royal Society B, 363, 3477-3488.

Whiten, A., \& VAN SchaIK, C. P. (2007). The evolution of animal "cultures" and social intelligence. Philosophical Transactions of the Royal Society B, 362, 603-620.

ZANN, R. (1990). Song and call learning in wild zebra finches in southeast Australia. Animal Behaviour, 40, 811-828. 